\title{
Should Lecture Recordings Be Mandated in Dental Schools? Two Viewpoints
}

\author{
Viewpoint 1: Lecture Recordings Should Be Mandatory in \\ U.S. Dental Schools
}

\author{
Andrea Ferreira Zandona, DDS, MSD, PhD; Janet Kinney, RDH, MS; \\ WookJin Seong, DDS, MS, PhD
}

\section{Viewpoint 2: Lecture Recordings Should Not Be Mandatory in U.S. Dental Schools}

\begin{abstract}
Vandana Kumar, DDS, MDS, MS; Alexander Bendayan, DDS; Edmond Hewlett, DDS
Abstract: Transcription or recording of lectures has been in use for many years, and with the availability of high-fidelity recording, the practice is now ubiquitous in higher education. Since technology has permeated education and today's tech-savvy students have expectations for on-demand learning, dental schools are motivated to record lectures, albeit with positive and negative implications. This Point/Counterpoint article addresses the question of whether lecture recording should be mandatory in U.S. dental schools. Viewpoint 1 supports the statement that lecture recording should be mandatory. Proponents of this viewpoint argue that the benefits - notably, student satisfaction and potential for improvement in student performance-outweigh concerns. Viewpoint 2 takes the opposite position, arguing that lecture recording decreases students' classroom attendance and adversely affects the morale of educators. Additional arguments against mandatory lecture recordings involve the expense of incorporating technology that requires ongoing support.
\end{abstract}

Dr. Zandona is Associate Professor, Department of Operative Dentistry, University of North Carolina at Chapel Hill School of Dentistry; Prof. Kinney is Clinical Associate Professor and Director of Dental Hygiene, Department of Periodontics and Oral Medicine, University of Michigan School of Dentistry; Dr. Seong is Associate Professor and Director, Division of Prosthodontics, Department of Restorative Sciences, University of Minnesota School of Dentistry; Dr. Kumar is Associate Professor, Division of Oral and Maxillofacial Radiology, Department of Oral Pathology, Medicine, and Oral Radiology, University of MissouriKansas City School of Dentistry; Dr. Bendayan is Clinical Associate Professor and Clinical Director of Prosthodontics, Department of Restorative Sciences and Biomaterials, Boston University Goldman School of Dental Medicine; and Dr. Hewlett is Professor, Section of Restorative Dentistry and Associate Dean of Outreach and Diversity, University of California, Los Angeles School of Dentistry. Direct correspondence to Dr. Vandana Kumar, Department of Oral Pathology, Medicine, and Oral Radiology, School of Dentistry, University of Missouri-Kansas City, 650 E. 25th Street, Kansas City, MO 64108; 816-235-2664; kumarva@umkc.edu.

Keywords: dental education, teaching method, educational technology, computer-assisted instruction, lecture recording, podcast

Submitted for publication 2/17/16; accepted 6/11/16

$\mathrm{T}$ echnology permeates all aspects of life today, creating a culture of "know it now" instant access to information. This trend has been clear in higher education for many years, with numerous technology-based tools-including recoding of lectures for on-demand viewing by students - being used to better engage digitally native students. Since technology is ubiquitous in higher education and today's tech-savvy students have expectations for on-demand learning, dental schools are motivated to record lectures, albeit with positive and negative implications. This Point/Counterpoint article addresses the question of whether lecture recording should be mandatory in U.S. dental schools. This discussion encompasses all types of lecture capture, including audiorecordings to be available as podcasts and systems that allow recording of cursor movement, typing, and other onscreen activity with audio voiceover. 


\section{Viewpoint 1: Lecture Recordings Should Be Mandatory in U.S. Dental Schools}

This viewpoint presents the case for why lecture recording should be an integral part of dental education in the U.S. Our current students include both millennials (Generation Y) and post-millenials (Generation Z). These students have grown up in the technological age and, as such, are well versed in technology and accept it as an active part of their lives. Students' familiarity with technology has translated into expectations for asynchronous and on-demand learning. ${ }^{1-4}$ Horvath et al. found in their 2010-11 study that $62 \%$ of the 45 responding North American dental schools provided some type of lecture capturing. ${ }^{5}$ Other studies have found that the impetus for recording lectures varied, with some schools wanting to modify their teaching approach to one of a flipped classroom. ${ }^{1,4-7}$ For other schools, recording lectures is an effective way to keep students abreast of course materials while they are in remote outreach clinics fulfilling clinical requirements. Still other schools have incorporated lecture recording in response to student demand. Some schools have mandated that all lectures be recorded and available to students; others have taken an opt-out/opt-in approach; and others have encouraged faculty members to prerecord lectures for online courses. While the reasons and protocols for lecture recordings vary, what appears to be a constant is the demand and trend in this educational approach. This viewpoint supports the argument for mandatory lecture recordings by presenting evidence from both students' and faculty members' perspectives.

\section{Students' Perspective}

Current students born in the digital age expect to have access to lecture content at their convenience. Dental students, many with a strong inclination for visual learning, prefer robust visual presentations and the ability to take notes. ${ }^{8,9}$ It is not surprising then that these students appreciate lecture recording, especially when video is a component of the recording. Usually lecture recording is used to supplement live lectures and text content ${ }^{2,10}$ and is preferred over straight lecture transcripts. ${ }^{1}$ This preference is likely related to the flexibility rendered by lecture recording whereby students can listen at their own time and at increased speed. ${ }^{1,4,10-13}$ Access to lecture recording has received positive reviews by students. Most likely, the reason for this favorable response is the perceived notion that, by viewing recorded lectures at students' own speed, knowledge acquisition is improved. ${ }^{11}$ Furthermore, students have reported satisfaction with lecture recording, ${ }^{1,11}$ as long as it does not replace interactions with their faculty members ${ }^{13,14}$ and the technology is efficient. ${ }^{12,13}$

Although faculty members tend to view lecture attendance as an integral part of learning and professional socialization process, students have been found to view lecture attendance as a tool for learning factual material. ${ }^{15}$ Studies have found that students decide to attend lectures if they feel it will positively affect their learning; thus, they consider their own learning style as well as the teaching style of the lecturer, irrespective of the availability of lecture recordings. ${ }^{11,15-18}$ Even though the impact of lecture recording on student performance is not clear, it might improve performance, especially if a proper pedagogical approach is used. Several studies have found a significant improvement in students' performance when using lecture recording, ${ }^{1,2,19-21}$ while others have found no association between performance and lecture recording. ${ }^{1,22-24}$ Interestingly, two studies reported that students who disfavored lecture recording had improved performance when it was available. ${ }^{21,25}$ The flipped classroom model seems to fully support lecture recording; in that methodology, in which students learn material through online lectures prior to the scheduled class and the class time is used for discussion and interactive activities, lecture recording was found to improve student performance. ${ }^{26}$

\section{Faculty Perspective}

Lecture recording also allows faculty members to provide a variety of presentation modes that enable student learning by incorporating principles of adult learning. ${ }^{27}$ Through lecture recordings, studies have found that integration of active learning focusing on case and problem assimilation was facilitated..$^{5,26}$ Other studies have found that courses became more interactive and student engagement increased. ${ }^{6,28}$ Recording of lectures also provides an opportunity for faculty members to engage in self- and peer evaluation, further supporting faculty development and improving teaching strategies. ${ }^{29}$ 
Table 1. Advantages of mandated lecture recordings: Viewpoint 1

\begin{tabular}{ll} 
Category & Reason \\
\hline $\begin{array}{l}\text { Student satisfaction } \\
\text { Student performance }\end{array}$ & $\begin{array}{l}\text { Students have more flexibility to review content at their own time and speed. } \\
\text { Potential for improved performance, especially if lecture recording is used for active learn- } \\
\text { ing. }\end{array}$ \\
$\begin{array}{l}\text { Increased faculty-student } \\
\text { interaction }\end{array}$ & $\begin{array}{l}\text { When lecture recording is used as a supplement to class time, faculty members can } \\
\text { increase interaction with students and student engagement. }\end{array}$ \\
$\begin{array}{l}\text { Opportunity for self- and peer } \\
\text { evaluation for faculty }\end{array}$ & $\begin{array}{l}\text { Recorded lectures can be used for faculty development and improving teaching } \\
\text { skills. }\end{array}$ \\
$\begin{array}{l}\text { Avoid potential intellectual } \\
\text { property concerns }\end{array}$ & $\begin{array}{l}\text { With mandatory lecture recordings on school servers, there is no reason for } \\
\text { individual students to record lectures on their own devices. }\end{array}$
\end{tabular}

When students record lectures using their own devices and subsequently share the recording with others, issues of intellectual property arise. However, if the lecture recording is done by the institution, some of these concerns may be alleviated. ${ }^{28,30,31}$ International copyright laws protect all forms of digital information and balance educational needs with authors' rights. ${ }^{30}$ In the United States, a Creative Commons license supports owners' rights by allowing them to determine the level of copyright protection desired. Privacy issues can be addressed by editing lecture contents carefully prior to publishing. McGowan et al. also reported that some faculty concerns are alleviated by only allowing lecture access through secure servers. ${ }^{27}$ While this practice does not prevent material from being copied, it does add a layer of protection for faculty members. As lecture recording becomes more common, faculty development at the institutional level will be needed to educate faculty members about benefits and proper use prior to initiating a mandate for lecture recording. ${ }^{5}$

When full consideration is given to the critical aspects of lecture recording, this educational approach may provide many benefits to both students and faculty members (Table 1). An initial investment in sophisticated equipment, coupled with ongoing IT support and faculty development, will facilitate a seamless transition to compulsory lecture recording in academic dental institutions. We believe that expected outcomes of mandatory lecture recording may include improved student satisfaction, augmentation of student learning, more options in faculty teaching strategies, and increased opportunity for faculty peer coaching.

\section{Viewpoint 2: Lecture Recordings Should Not Be Mandatory in U.S. Dental Schools}

In this viewpoint, we contend that lecture recordings should not be mandatory in U.S. dental schools and argue that, when it is used, it should be in conjunction with other learning strategies. The practice of lecture recording has not been devoid of controversy. While some educators readily embrace recording of all lectures and use this opportunity to increase active learning, as seen in flipped classroom approaches, others are concerned that lecture recording will encourage unexcused student absenteeism. Although students are usually supportive of lecture recording because it gives them more control over when and how they learn, studies have found that students do not want online lectures to substitute for student-faculty interactions. ${ }^{13,14}$ Rather than mandating that lectures be recorded, we recommend a more thoughtful, measured approach to the use of this tool, employing it selectively and synergistically with other modalities tailored to the specific characteristics (content, class level, instructor's strengths) of each course. We present pertinent considerations regarding lecture recording and highlight the disadvantages of making it mandatory.

\section{Attendance and Cost Issues}

A study examining faculty and student opinions regarding lecture recordings across a three-year PharmD curriculum found that the practice negatively influenced live attendance of students. ${ }^{32}$ With the availability of lecture recordings, the expected decrease in 
attendance is between $10 \%$ and $20 \% .{ }^{11,33}$ Widespread student absence in the classroom can be detrimental to educators' morale. ${ }^{34}$ Furthermore, faculty incentive to incorporate interactive, dynamic in-class activities is substantially reduced, ultimately having a negative impact on student learning. ${ }^{34}$ Lecture recording does not support dynamic student/lecturer interaction, and students lose the opportunity to ask questions in a classroom environment and practice face-to-face interpersonal social skills that enhance learning. ${ }^{31}$ Classroom absenteeism has also been found to decrease student participation in professional organizations. ${ }^{31}$ Professional socialization of students is especially important in the health professions because this process imparts professional attitudes and values.

Implementation of lecture recording requires universities to invest in sophisticated and expensive systems to provide good quality audio and video recording; this commitment of funds must be ongoing to provide essential IT support for maintaining the functionality of such systems. ${ }^{13}$ Faculty members also require training and ongoing support to properly use this new technology. Inertia and resistance to change can pose a challenging barrier to faculty members ${ }^{35}$ in that some are enthusiastic early adopters of opportunities for change whereas others are skeptical., ${ }^{5,36}$

\section{Effects of Lecture Recordings on Students}

Students are more familiar with the digital world, but they do not as frequently access recorded lectures as some may think. Lecture recording, as an innovative modality, appears to have had initial fascination among students, but it wears off rather quickly. A study by Marchand et al. on lecture recording in pharmacy education found that, during its first year of implementation, the number of individual accesses to recorded lectures was high, but many recordings were viewed only for a short time. ${ }^{32}$ During the second year of that study, the number of individual accesses was $42 \%$ lower than during the first year, but the viewing time for all recordings was $13 \%$ longer, indicating that students were making more selective use of the recordings. This finding is consistent with research that suggests an extrinsic motivator, such as access to a new learning tool, provides an initial motivation boost because of its novelty but the effect is often short-lived..$^{18,31}$

Evidence suggests the learning benefits experienced by students when recorded lectures are available are also debatable. Faculty members in one study saw no difference in class grade averages compared with those achieved by previous cohorts. ${ }^{32}$

\section{Copyright and Other Issues}

Copyright issues regarding recorded lectures are another factor that contributes to faculty hesitancy to adopt lecture recording. ${ }^{37}$ Faculty members are concerned about intellectual property violations ${ }^{32}$ and ownership of recordings. ${ }^{5}$ In a survey of U.S. dental schools, nine of 25 respondents reported that their schools retained ownership of the recordings, while 12 reported that faculty members retained ownership and four were uncertain about the legal status of their lecture recordings. ${ }^{5}$ In the same study, inconsistency in lecture recording guidelines was found to exist between various courses and within the same course in the same institution - a lack of uniformity in the platform for student learning. Twelve of 28 schools responded that they record almost all lectures, while 16 of the schools recorded only some lectures. This inconsistency is supported by a paucity of widely accepted guidelines for application and implementation of lecture recording and a lack of resources for producing a curriculum to suit all students' needs.

We acknowledge that the learning effectiveness of traditional lecturing can be enhanced by incorporating in-class active learning strategies such as audience response systems, planned discussions, and online or offline quizzes, as well as discussion forums, online sessions, and small group seminars to supplement or replace some lecture sessions. Undergraduate students in classes with traditional stand-and-deliver lectures were found to be 1.5 times more likely to fail than students in classes utilizing more stimulating active learning methods ${ }^{38}$ Specific recommendations for making lectures more attractive to students include asking learners plenty of questions during a presentation, providing opportunities to share answers with each other and the class, and always linking learning to assessment. The strength of evidence for active learning effectiveness suggests that investing in robust faculty development to enable traditional lecturers' use of more impactful teaching methods would be worthwhile. ${ }^{38,39}$

Overall, while lecture recording can be an effective supplemental learning tool, controversy regarding its benefits is revealed in the evidence (Table 2). On the educators' side, skeptical faculty members are concerned that lecture recording will encourage unexcused student absenteeism. Although students are usually more supportive of lecture recording because it can give them more control over learning, they do not 
Table 2. Disadvantages of mandated lecture recording: Viewpoint 2

\begin{tabular}{|c|c|}
\hline Category & Reason/s \\
\hline $\begin{array}{l}\text { Attendance and student-teacher } \\
\text { interaction }\end{array}$ & $\begin{array}{l}\text { Adverse effect on both attendance and educator morale. Less incentive to make } \\
\text { in-class experience more dynamic. Students lose opportunities to actively engage teacher } \\
\text { and peers with questions and comments and to build and practice verbal communication } \\
\text { skills in a dynamic classroom environment. }\end{array}$ \\
\hline Cost & $\begin{array}{l}\text { Investment in lecture recording technology, ongoing IT support, and periodic system up- } \\
\text { grade or replacement puts a high demand on institutional budgets. }\end{array}$ \\
\hline Faculty buy-in & Wide variation among educators' motivations to embrace and adapt to the new technology. \\
\hline Value & Improvement in academic performance as a direct result of lecture recording is debatable. \\
\hline Copyright and ownership & $\begin{array}{l}\text { Concerns by faculty members over insufficient protections for and loss of control over distri } \\
\text { bution of their intellectual property. Policies regarding ownership of lecture vary widely or } \\
\text { have not been established. }\end{array}$ \\
\hline Guidelines and standards & $\begin{array}{l}\text { Institutions experience barriers to ensuring consistency and uniformity in lecture recording } \\
\text { implementation and quality across and within courses, creating a non-uniform platform for } \\
\text { student learning. }\end{array}$ \\
\hline $\begin{array}{l}\text { Need for faculty development in } \\
\text { active learning }\end{array}$ & $\begin{array}{l}\text { Enables traditional lecturers' use of more impactful teaching methods, e.g., in-class } \\
\text { discussions and debates, small-group seminars, and online discussion forums and quizzes } \\
\text { to supplement or replace some traditional lecture sessions. }\end{array}$ \\
\hline
\end{tabular}

want online lectures to substitute for student-faculty interactions. Even with expected student satisfaction, there still is a need for well-designed studies regarding the impact of lecture recording on academic performance, especially in dental education. Finally, we contend that any investment in lecture recording infrastructure may be better used for-or should at least be balanced by-investments in robust faculty development programs in active learning strategies.

\section{Response by Dr. Zandona, Prof. Kinney, and Dr. Seong to Viewpoint 2:}

The digital world is changing how students are being educated. Lecture recording should not be used as a substitute for live lectures, but a supplement that allows class time to be used for student-faculty interactive time. Embracing new technology brings the prospect of incorporating many models of active learning that have been found to improve academic performance. The use of lecture recording as a supplement has the potential to improve student-faculty interaction and faculty and student satisfaction. We agree that the benefits of mandating lecture recording for all courses in dental school have not been demonstrated. Cost is also a significant issue. However, there are systems that can be seamlessly integrated that require no faculty training on lecture recording, thereby eliminating some of these perceived barriers. Faculty training regarding how to use lecture recording as an educational supplement to live lectures is an issue that must be addressed to prevent the drawbacks that can occur if lecture recording is used only as a substitute to live lectures.

\section{Response by Drs. Kumar, Bendayan, and Hewlett to Viewpoint 1:}

We agree that recording lectures has the potential to address the perceived need to provide a transformative connection between technology and learning, but Viewpoint 1 does not take into consideration that very few dental schools have the technology in place or the budget to provide highdefinition recordings. Dental schools have yet to define the copyright issues associated with lecture recording and to implement policies regarding recording lectures of all or some courses. Furthermore, the lack of IT support to faculty members who may not have the skills, experience, or training will likely be an impediment. We strongly believe dental schools should provide lecture recording as a service, but many cost-benefit questions remain unanswered to support it as a mandated practice.

\section{REFERENCES}

1. Allen KL, Katz RV. Comparative use of podcasts vs. lecture transcripts as learning aids for dental students. J Dent Educ 2011;75(6):817-22.

2. Kalludi SN, Punja D, Pai KM, Dhar M. Efficacy and perceived utility of podcasts as a supplementary teaching aid among first-year dental students. Australas Med J 2013;6(9):450. 
3. Twenge JM. Generational changes and their impact in the classroom: teaching generation me. Med Educ 2009;43(5):398-405.

4. Brittain S, Glowacki P, Van Ittersum J, Johnson L. Podcasting lectures. Educause Q 2006;3(24):10.

5. Horvath Z, O'Donnell JA, Johnson LA, et al. Use of lecture recordings in dental education: assessment of status quo and recommendations. J Dent Educ 2013;77(11):1431-42.

6. Park SE, Howell TH. Implementation of a flipped classroom educational model in a predoctoral dental course. $\mathrm{J}$ Dent Educ 2015;79(5):563-70.

7. Schleyer TK, Thyvalikakath TP, Spallek H, et al. From information technology to informatics: the information revolution in dental education. J Dent Educ 2012;76(1):142-53.

8. Breckler J, Joun D, Ngo H. Learning styles of physiology students interested in the health professions. Adv Physiol Educ 2009;33(1):30-6.

9. Murphy RJ, Gray SA, Straja SR, Bogert MC. Student learning preferences and teaching implications. J Dent Educ 2004;68(8):859-66.

10. Pilcher ES. Students' evaluation of online course materials in fixed prosthodontics: a case study. Eur J Dent Educ 2001;5(2):53-9.

11. Cardall S, Krupat E, Ulrich M. Live lecture versus videorecorded lecture: are students voting with their feet? Acad Med 2008;83(12):1174-8.

12. Klein KP, Hannum WH, Fields HW, Proffit WR. Interactive distance learning in orthodontic residency programs: problems and potential solutions. J Dent Educ 2012;76(3):322-9.

13. Kunin M, Julliard KN, Rodriguez TE. Comparing face-to-face, synchronous, and asynchronous learning: postgraduate dental resident preferences. J Dent Educ 2014;78(6):856-66.

14. McCann AL, Schneiderman ED, Hinton RJ. E-teaching and learning preferences of dental and dental hygiene students. J Dent Educ 2010;74(1):65-78.

15. Zazulia AR, Goldhoff P. Faculty and medical student attitudes about preclinical classroom attendance. Teach Learn Med 2014;26(4):327-34.

16. Mattick K, Crocker G, Bligh J. Medical student attendance at non-compulsory lectures. Adv Health Sci Educ 2007;12(2):201-10.

17. Billings-Gagliardi S, Mazor KM. Student decisions about lecture attendance: do electronic course materials matter? Acad Med 2007;82(10):S73-6.

18. Gupta A, Saks NS. Exploring medical student decisions regarding attending live lectures and using recorded lectures. Med Teacher 2013;35(9):767-71.

19. Bacro TR, Gebregziabher M, Fitzharris TP. Evaluation of a lecture recording system in a medical curriculum. Anat Sci Educ 2010;3(6):300-8.

20. Boynton JR, Johnson LA, Nainar SH, Hu JC. Portable digital video instruction in predoctoral education of child behavior management. J Dent Educ 2007;71(4):545-9.

21. Richardson D. Student perceptions and learning outcomes of computer-assisted versus traditional instruction in physiology. Am J Physiol 1997;273(6 Pt 3):S55-8.
22. Chen M, Horrocks E, Evans R. Video versus lecture: effective alternatives for orthodontic auxiliary training. J Orthod 1998;25(3):191-5.

23. Paul S, Pusic M, Gillespie C. Medical student lecture attendance versus iTunes U. Med Educ 2015;49(5):530-1.

24. Solomon DJ, Ferenchick GS, Laird-Fick HS, Kavanaugh $\mathrm{K}$. A randomized trial comparing digital and live lecture formats. BMC Med Educ 2004;4(1):27.

25. Williams C, Aubin S, Harkin P, Cottrell D. A randomized, controlled, single-blind trial of teaching provided by a computer-based multimedia package versus lecture. Med Educ 2001;35(9):847-54.

26. Wakabayashi N. [Flipped classroom as a strategy to enhance active learning]. J Stomatol Soc Japan 2015;81:1-7. [in Japanese]

27. McGowan J, Abrams M, Frank M, Bangert M, eds. Creating a virtual community of learning predicated on medical student learning styles: AMIA annual symposium proceedings. Bethesda, MD: American Medical Informatics Association, 2003.

28. Davidson LA. The end of print: digitization and its consequence - revolutionary changes in scholarly and social communication and in scientific research. Int $\mathrm{J}$ Toxicol 2005;24(1):25-34.

29. Baek S, Im SJ, Lee SH, et al. Instructional analysis of lecture video recording and its application for quality improvement of medical lectures. Korean J Med Educ 2011;23(4):263-74.

30. Johnson L, Grayden S. Podcasts: an emerging form of digital publishing. Int J Comput Dent 2006;9(3):205-18.

31. Maynor LM, Barrickman AL, Stamatakis MK, Elliott DP. Student and faculty perceptions of lecture recording in a doctor of pharmacy curriculum. Am J Pharm Educ 2013;77(8)

32. Marchand JP, Pearson ML, Albon SP. Student and faculty member perspectives on lecture capture in pharmacy education. Am J Pharm Educ 2014;78(4).

33. Soong SKA, Chan LK, Cheers C, Hu C. Impact of videorecorded lectures among students. Who's Learning 2006:789-93

34. Westrick SC, Helms KL, McDonough SK, Breland ML. Factors influencing pharmacy students' attendance decisions in large lectures. Am J Pharm Educ 2009;73(5):1.

35. Prober CG, Heath C. Lecture halls without lectures: a proposal for medical education. N Engl J Med 2012;366(18):1657-9.

36. Bickerdike S, Whittle SR, Pickering JD. Do lecture audiorecordings support engagement and flexible learning? Med Educ 2014;48(5):522-3.

37. Mair J. Who owns the information in the medical record? Copyright issues. Health Inform Manag J 2011;40(3):31.

38. Making lectures unmissable! Tomorrow's Professor eNewsletter, Stanford Center for Teaching and Learning. At: cgistanfordedu/ dept-ctl/cgi-bin/tomprof/ enewsletterphp?msgno=1365. Accessed 21 Apr. 2016.

39. Freeman S, Eddy SL, McDonough M, et al. Active learning increases student performance in science, engineering, and mathematics. Proc Nat Acad Sci 2014;111(23): 8410-5. 